\title{
No acute effect of whole-body vibration on Roundhouse kick and countermovement jump performance of competitive Taekwondo athletes
}

\section{Efeito agudo da vibração de corpo inteiro no desempenho do chute Roundhouse e no salto com contramovimento em atletas competitivos de Taekwondo}

\author{
Mariana Paulino Oliveira \\ Darryl Cochrane ${ }^{2}$ \\ Marcos Daniel Motta Drummond ${ }^{1}$ \\ Maicon Rodrigues Albuquerque \\ Pedro Augusto Santos Almeida ${ }^{1,3}$ \\ Bruno Pena Couto
}

Abstract - Little is known about the effect of whole body vibration (WBV) has on specific sports action such as taekwondo kicking technique. Fifteen individuals (10 males and 5 females; $18.6 \pm 2.1$ years), performed two experimental protocols on separate days: A) 1 minute exposure at $26 \mathrm{~Hz}$ frequency of WBV followed by countermovement jump (CMJ) test; B) 1 minute exposure at $26 \mathrm{~Hz}$ frequency of WBV followed by kick test. A Student's t-Test analysis was performed to evaluate the difference between performance before and after vibration intervention. The CMJ height means $(\mathrm{cm})$ were $34.1 \pm 6.4$ before and $34.2 \pm 6.5$ after $\mathrm{WBV}$ exposure. The CMJ maximal force means were 1582.6 \pm 214.3 before WBV and $1595.7 \pm 205.0$ after WBV, while Impulse means (N.s) were $283.3 \pm 48.6$ before WBV and $282.6 \pm 46.6$ after WBV. The kick time means (ms) were $219.9 \pm 20.31$ before WBV and 218.9 \pm 19.81 after WBV. No significant differences were found regarding the application of mechanical vibration for all variables. Thus, the vibration intervention ( 1 minute of WBV at $26 \mathrm{~Hz}$ and $6 \mathrm{~mm}$ ) adopted in this present study may have not been substantial to improve Roundhouse kick time ( $\mathrm{p}=0.73$ ), jump height $(\mathrm{p}=0.80)$, maximal force $(\mathrm{p}=0.78)$ and impulse $(\mathrm{p}=0.38)$ of taekwondo athletes. Future studies should investigate new vibration protocols (amplitude, frequency) and training (intensity, exercise, duration) to determine optimal parameters.

Key words: Martial arts; Muscle strength; Sports; Vibration.

Resumo - Pouco se sabe sobre o efeito da vibração de corpo inteiro (VCI) sobre o desempenho de açôes esportivas especificas, como a técnica de chute do Taekwondo. Para isso, 15 atletas (10 homens e 5 mulheres; 18,6 \pm 2,1 anos) realizaram dois protocolos experimentais em dias separados: A) pré-teste de salto com contramovimento (SCM), seguido de 1 minuto de exposição à frequência de $26 \mathrm{~Hz}$ de VCI e pós-teste de SCM; B) pré-teste de chute Roundhouse, seguido de 1 minuto de exposição à frequência de $26 \mathrm{~Hz}$ de VCI e pós-teste chute Roundhouse. A análise do teste $t$-Student foi realizada para verificar a diferença entre o desempenho pré e pós a aplicação da VCI. As médias de altura dos $S C M(\mathrm{~cm})$ foram $34,1 \pm 6,4$ pré e $34,2 \pm 6,5$ pós a VCI. As médias de força máxima no SCM foram 1582,6 $\pm 214,3$ prée 1595,7 $\pm 205,0$ pós a VCI, enquanto as médias de Impulso (N.s) foram 283,3 $\pm 48,6$ pré e 282,6 46,6 pós a VCI. O tempo de chute (ms) foi de 219,9 20,31 pré e 218,9 $\pm 19,81$ pós a VCI. Não foram encontradas diferenças significativas em relação à aplicação de vibração mecânica para todas as variáveis. Assim, a intervenção proposta (1 minuto de VCI à $26 \mathrm{~Hz}$ e $6 \mathrm{~mm}$ ) no presente estudo pode não ter sido adequada para aumentar o desempenho no teste de chute Roundhouse ( $p=0,73)$, a altura ( $p$ $=0,80)$, força máxima $(p=0,78)$ e impulso no SCM $(p=0,38)$ de atletas competitivos de Taekwondo. Estudos futuros deveriam investigar novas configuraçôes de protocolos de vibração (amplitude, frequência) e treinamento (intensidade, exercício, duração) para determinar parâmetros ótimos para melhoria do desempenho esportivo.

Palavras-chave: Artes marciais; Esporte; Força muscular; Vibração.
1 Universidade Federal de Minas Gerais. Escola de Educação Física, Fisioterapia e Terapia Ocupacional. Belo Horizonte, MG. Brasil.

2 Massey University. New Zealand

3 Universidade de Itaúna. Itaúna, MG. Brasil

Received: October 22, 2017 Accepted: April 17, 2018 


\section{INTRODUCTION}

The ability to generate high power output is essential for sporting success, especially for combat sports such as taekwondo that requires athletes to have a high peak of anaerobic power of the lower limbs. Taekwondo is characterized as an intermittent high-intensity sport, which demands motor actions of high and spinning kicks, jumps, changes of direction that control the distance between the opponent in preparation of subsequent kicks ${ }^{1}$. Recent studies have demonstrated that exposure to mechanical vibration can increase muscle strength and power acutely and chronically ${ }^{2,3}$, and improve athletic performance 4 . For this aim, in the last decade, there has been growing interest to investigate the application of mechanical vibration. However, its effect on performance of specific movements requires further exploration ${ }^{2}$.

Exercise with vibration exposure is a method of neuromuscular training that has been used by athletes and non-athletes. During the application of mechanical vibrations, the muscle may produce a contraction reflex referred to as tonic vibration reflex (TVR), which occurs through a sequence of fast muscle stretching actions ${ }^{5}$. It has been proposed that the vibration stimulus causes the activation of alpha motor neurons in response from the afferent neurons of muscle spindles ${ }^{5}$. If muscle is potentiated from vibration it would benefit athletic activities that utilize the stretch-shortening cycle ${ }^{6}$, such as the counter movement jump (CMJ). Additionally, it has been suggested that the vibration stimulus is most effective when physical performance actions are performed rapidly ${ }^{7}$.

To date, acute studies investigating the effects of vibration training on sports performance have been limited to the assessment of vertical jump performance where the majority of the research have reported an improvement in vertical jump height ${ }^{2,8}$. However, determining the possible effects of mechanical vibration applied to specific sporting actions of different physical skills is limited, which indicates the need for additional and specific tests for the sports modality investigated. Bunker et al..$^{9}$ demonstrated that $30 \mathrm{~s}$ of eight exercises performed on a whole body vibration (WBV) platform at $50 \mathrm{~Hz}$ enhanced golf driving performance. Similarly, Reyes et al. ${ }^{10}$ reported that baseball bat speed increased from acute WBV exposure.

With the potential to increase sporting movements of golf and baseball, the effects of WBV to enhance taekwondo performance warrants further investigation. Therefore, the aim of this study was to investigate the effect of WBV on CMJ and roundhouse kick performance in taekwondo athletes. We hypothesized that acute WBV would result in a greater increase in performance of the lower extremities compared to without WBV and, because of the complexity of each technique, we hypothesized that CMJ height and kick time would respond different to an acute bout of vibration.

\section{METHODOLOGICAL PROCEDURES}

\section{Participants}

Fifteen red and black belt taekwondo athletes (10 males and 5 females; age 
$18.6 \pm 2.1$ years; body mass $61.7 \pm 7.6 \mathrm{~kg}$ and height $1.73 \pm 0.06 \mathrm{~m}$ ) volunteered for the study. Inclusion criteria were that subjects had been involved in strength, specific Taekwondo training for at least one year (i.e., defined as consistently lifting weights and specific taekwondo tactical, technical and physical training at least 3 times per week for a minimum of one year) and compete at least in the national championships. Participants were informed about the nature of this study and signed an informed consent form according to the International Review Board for the use of human subjects at research. All procedures were approved by the Federal University of Minas Gerais Ethical Committee for Research (49553815.4.0000.5149). All athletes were engaged in Taekwondo training program at least $3 \mathrm{x} /$ week for more than one year.

\section{Procedures and measures}

The study consisted of two protocols: countermovement (CMJ) and roundhouse kick. The protocol order was randomized and was performed on separate days, 24 hrs apart. All participants were familiarized with CMJ and roundhouse kick test prior to testing. No warm-up was performed.

\section{Vibration intervention}

Participants were exposed to a single bout of one-minute sinusoidal WBV using a vibrating platform (Planet Fitness, EN 004 Professional model) with adapted engine (WEG, IP55 model, $2 \mathrm{HP}$ of power, frequency 60 $\mathrm{Hz}$ and $1740 \mathrm{rpm}$ rotation) (Figure 1). Participants were instructed to keep their knees flexed $\left(10^{\circ}\right)$, feet parallel and positioned at a predetermined location to ensure a peak-to-peak amplitude of $6 \mathrm{~mm}$ with a fixed vibration frequency of $26 \mathrm{~Hz}^{2}$.

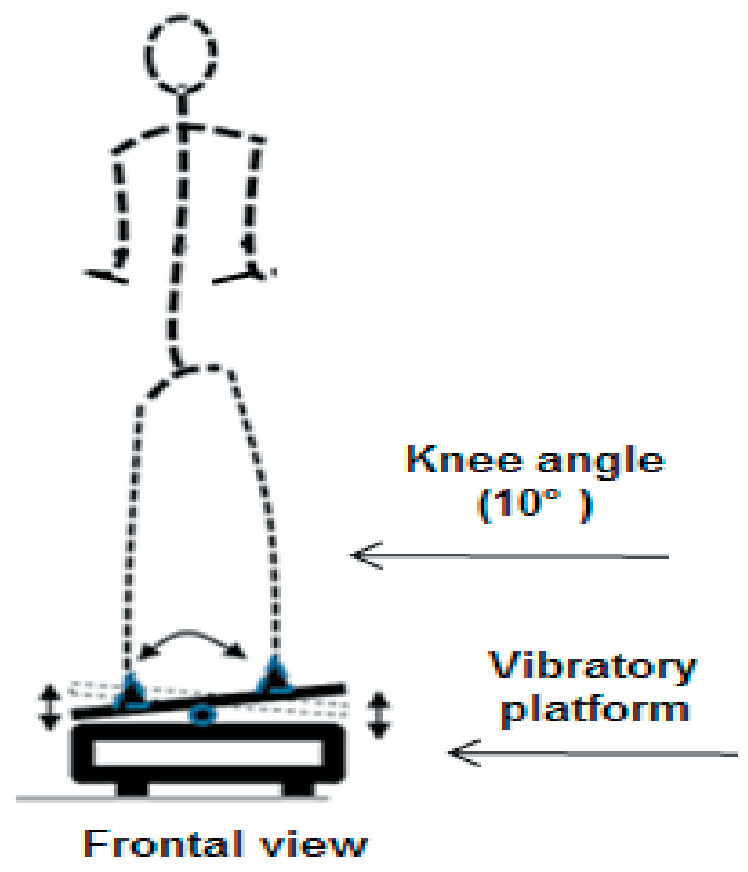

Figure 1. The position assumed on the vibrating plate. 


\section{CIMJ Protocol}

The CMJ was used to evaluate the height of the jump by combining eccentric and concentric actions. Athletes positioned both feet on a force platform (PLA3-1D-7KN/JBA Zb. Staniak ${ }^{\circledR}$, Poland, $1000 \mathrm{~Hz}$; amplifier WTM 005-2T/2P JD Jaroslaw ${ }^{\oplus}$, Poland; software Max 5-Zb, Staniak ${ }^{\circledR}$, Poland). Athletes were instructed not to lift their knees during the flight and landing phases. The horizontal and lateral displacements were minimized and the hands were kept on the hips throughout the test. The angular displacement of the knees was standardized where athletes were required to bend their knees to approximately $90^{\circ}$. Three jumps were performed with a 30-s rest interval. The variables obtained from the force platform were: jump height $(\mathrm{cm})$, maximal force $(\mathrm{N})$, and impulse (N.s). After one minute, the athlete was exposed to one-minute vertical sinusoidal WBV using a vibratory platform. Five minutes after the vibration protocol ${ }^{2}$, the identical CMJ protocol was repeated.

\section{Roundhouse kick Protocol}

The roundhouse kick was selected due to it being the most frequent technique used in taekwondo ${ }^{11}$ which makes it a specific test of taekwondo performance. The kicking foot was placed on a contact mat (Multisprint, v. 3.5.7, Hidrofit Ltd, Brazil) where each athlete was instructed to kick as fast as possible to a taekwondo target pad that was positioned at a height of the athlete's iliac crest (HC). To ensure kicking reproducibility, the distance was incrementally marked in centimeters on the floor between the contact mat and the target pad Figure 2). This ensured that between trials the stance width of the kicking and non-kicking foot was positioned the same distance apart and that the distance between the kicking foot and the target pad remained identical (HD).

A computer was connected to the contact mat and target pad sensor where an armored inertial sensor was inserted into the target pad that had a closed electric circuit. Using Multisprint Full program (v. 3.5.7, Hidrofit Ltd, Brazil) the kick time (KT) was measured from when the kicking leg moved off the contact mat to when it made contact with the target pad (Figure 2).

All athletes executed three roundhouse kicks with an interval of 30 seconds between each repetition. After one minute, the athlete was exposed to one minute vertical sinusoidal WBV. Five minutes after the vibration protocol, the identical kick protocol was repeated.

\section{Statistical analysis}

Data normality was verified using the Shapiro-Wilk test. A paired t-test analysis was performed to evaluate the difference between performance before and after WBV. For this analysis, the average of the three values for $\mathrm{CMJ}$ and roundhouse kick were used. Additional analysis was performed using the best value from each variable. The highest values of maximum force and impulse were obtained from the highest jump. A value of $\mathrm{p}<0.05$ 

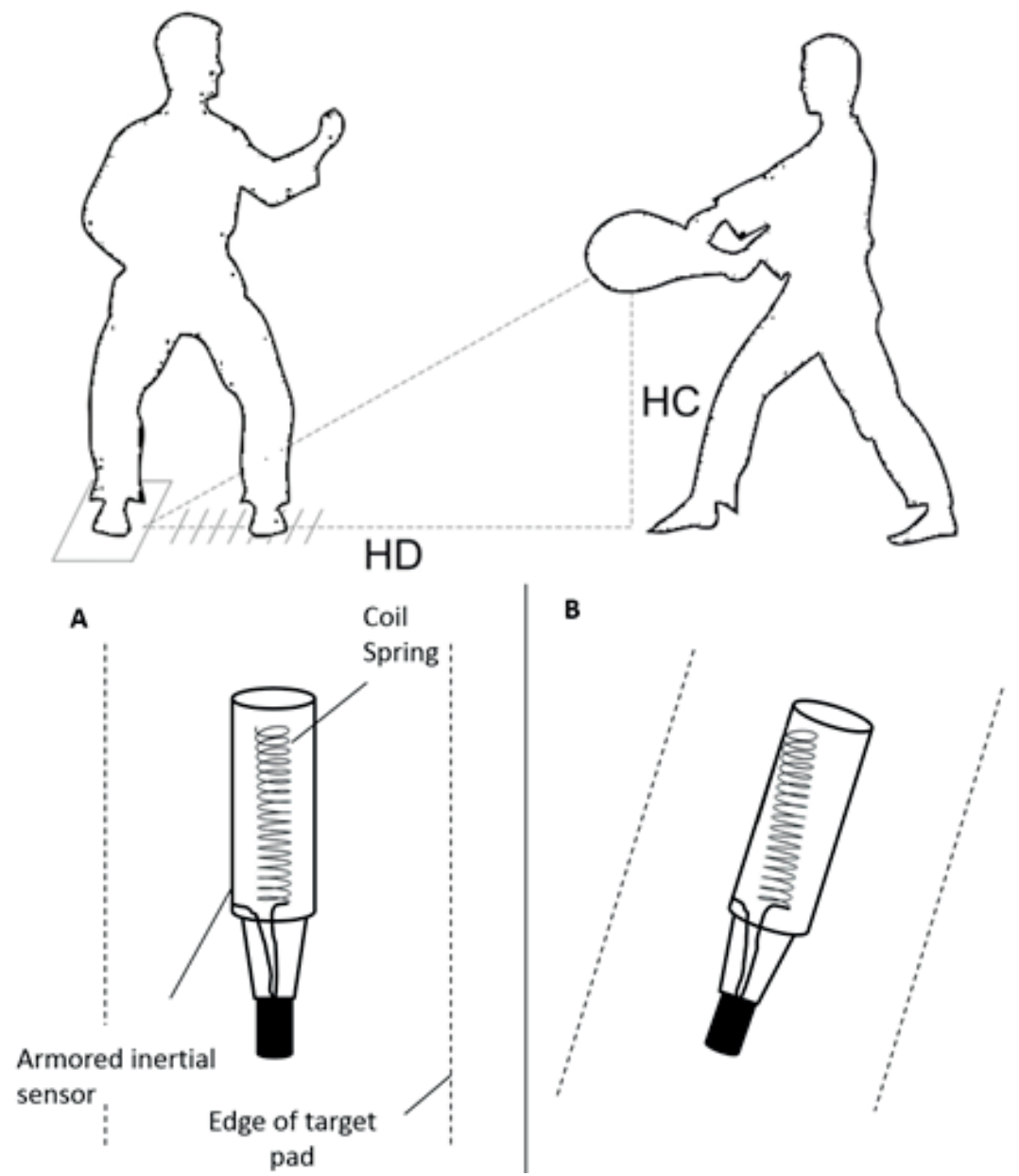

Figure 2. Roundhouse kick (model of the test and measurement criteria) and coupled inertial sensor inserted in the target pad: (A) - before the kick contact; (B) - after the kick contact (closed electronic circuit between the coil spring and the armored inertial sensor).

was set for statistical significance and group data is presented as mean \pm standard deviation (SD).

\section{RESULTS}

All values obtained from the tests were normally distributed.Table 1 presents the mean and standard deviation from the values obtained from all variables before and after WBV. No significant difference was obtained between the measures before and after WBV of kick time ( $\mathrm{p}=0.73)$, jump height $(\mathrm{p}=0.80)$, maximal force $(\mathrm{p}=0.78)$ and impulse $(\mathrm{p}=0.38)$.

Table 1. Mean and standard deviation of the variables before and after WBV

\begin{tabular}{lcc}
\hline Variables & Mean \pm SD Before WBV & Mean \pm SD After WBV \\
\hline Kick time $(\mathrm{s})$ & $0.22 \pm 0.2$ & $0.22 \pm 0.2$ \\
CMJ height $(\mathrm{cm})$ & $34.1 \pm 6.4$ & $34.2 \pm 6.5$ \\
CMJ maximal force $(\mathrm{N})$ & $1582.6 \pm 214.3$ & $1595.7 \pm 205.0$ \\
Impulse (N.s) & $283.3 \pm 48.6$ & $282.6 \pm 46.6$ \\
\hline
\end{tabular}

Note. Standard Deviation - SD; Countermovement Jump - CMJ; Whole Body Vibration - WBV. 


\section{DISCUSSION}

To the best of our knowledge, this is the first study to investigate the acute about of WBV on the specific performance of a taekwondo kick. For this study, we hypothesized that acute WBV would result in a greater increase in performance of the lower extremities compared to without WBV. Additionally, we hypothesized that muscular performance of CMJ height and kick time would respond differently to WBV. However, the hypothesis was not confirmed. The results showed that the exposure to WBV did not produce an acute positive or deleterious (limiting) effect in all variables investigated. A possible explanation for the nonexistence effects of WBV may be related to the protocol (exposure time and vibration intensity) and the type of vibration (WBV vs. local vibration). Another explanation could be the complexity of the task. It is plausible that WBV may not influence the roundhouse kick due to its intricate movement. It has been documented that the more complex action, the smaller the effect that vibration will have to optimizing performance ${ }^{12}$. This is supported by earlier research that demonstrated WBV failed to enhance sprint performance ${ }^{13}$. In contrast, the studies of Bunker et al. ${ }^{9}$ and Reyes et al. ${ }^{10}$ reported WBV improved multifaceted sporting movements.

The most common form of vibration for sports training is $\mathrm{WBV}^{12}$. It is postulated that WBV may have a greater vibration training effect on the muscles closer to the vibration source that has the ability to stimulate more muscle groups compared to local vibration ${ }^{26}$. However, the dissipation of the vibrations' energy during WBV transmission is often reduced by other body tissues and structures. Therefore, the energy that reaches the target muscle(s) is often attenuated when propagated through the body ${ }^{14}$. Rubin et al. ${ }^{15}$ reported that when standing $\left(20^{\circ}\right.$ knee flexion $)$ on a vibration platform, transmission was dampened by the hip and spine $(\sim 30 \%)$. For this reason, some authors have suggested the application of local vibration with individualized vibration frequency can assist to attenuate the dissipation of energy and enhance the outcome of vibration exposure ${ }^{16}$. Numerousstudies have reported positive effects of applying WBV to enhance vertical jump performance ${ }^{2,17-19}$. Torvinen et al. ${ }^{19}$ and Bosco et al. ${ }^{20}$, reported significant increases of $2 \%$ and $3.8 \%$ respectively in CMJ height. Torvinen et al. ${ }^{19}$ intervention consisted of 4 minutes of WBV, where vibration frequency was incrementally increased (15, 20, 25 and $30 \mathrm{~Hz}$ ). In comparison, Bosco et al. ${ }^{20}$ intermittent protocol of $10 \mathrm{x} 60$ s exposure with 60s rest was performed at a fixed vibration frequency $(26 \mathrm{~Hz})$. Similarly, an intermittent WBV protocol of $4 \times 30$ s reported a significant increase in CMJ and squat jump (SJ) height ${ }^{17}$. In contrast, short WBV duration exposure of 20s has shown to increase CMJ height by $8.5 \%{ }^{18}$, which is similar to the single exposure of the current study. Previous authors have explained the transient enhancement in CMJ by TVR ${ }^{21}$, however other factors such as, an increase in peripheral circulation $^{22}$, blood flow and skin temperature ${ }^{22}$, nerve conduction velocity ${ }^{3}$ and post-activation potentiation ${ }^{23}$ may also play a role. 
Nonetheless, in the present study we failed to show an increase in CMJ height, however it is feasible that the nonexistence increases in performance maybe due to the individual response of vibration transmission and resonance. In support of our current results other studies have reported no change in CMJ following a single bout (30s) $\mathrm{WBV}^{24}$ and repeated WBV exposure $^{25}$. This substantiates the claim that further research is required to determining an optimal WBV protocol (duration, intensity and recovery) for jump performance.

Nigg and Wakeling ${ }^{26}$ have reported a natural vibration frequency and suggest that lower-limb muscles of athletes respond in the range of 5-65 $\mathrm{Hz}$. Di Giminiani et al. ${ }^{27}$ found that the EMG activity of specific muscles was dependent on the magnitude of the vibration stimulus that reaches muscle. In the present investigation, we used the same vibration frequency $(26 \mathrm{~Hz})$ as Bosco et al. ${ }^{20}$ who demonstrated an increase in jump performance. However, Cardinale and $\mathrm{Lim}^{28}$ found that the largest increase in SJ was from $20 \mathrm{~Hz}$. According to these authors, high frequencies do not necessarily increase CMJ and SJ height. Conceivably, $26 \mathrm{~Hz}$ may increase the performance of lower limbs, but combining all the characteristics of our protocol (type of vibration [WBV], vibration frequency, exposure time) was not sufficient to induce improvements in CMJ and roundhouse kick time. Previous studies have emphasized the importance of individualizing the vibration frequency to produce greater effects on the neuromuscular system compared to a fixed frequency ${ }^{16,29}$. This is further supported by Luo et al. ${ }^{30}$ that further research should focus on the application to identifying an individual's vibration frequency for optimizing muscular performance.

\section{CONCLUSION}

There was no demonstrable difference in CMJ jump height, maximum force impulse and roundhouse kick time after a single bout of WBV. The likely explanation for this is probably due to the short duration of WBV exposure. Further studies should investigate different vibration protocols to maximized specific action in sports, such as taekwondo kicks.

\section{COMPLIANCE WITH ETHICAL STANDARDS}

\section{Conflict of interest statement}

The authors have no conflict of interests to declare.

\section{Ethical approval}

Ethical approval was obtained from the local Human Research Ethics Committee - Federal University of Minas Gerais, and the protocol was written in accordance with the standards set by the Declaration of Helsinki.

\section{Author Contributions}

Conceived and designed the experiments: M,B. Performed the experi- 
ments: M,P,B. Analyzed the data: M,M,M,B. Contributed reagents/ materials/analysis tools: M,M,M,B,P. Wrote the paper: M,M,M,B,P.

\section{REFERENCES}

1. Kazemi M, Perri GSD. A profile of 2008 Olympic Taekwondo competitors. J Can Chiropr Assoc 2010; 54:243-9.

2. Couto, BP, Silva, HR, Barbosa, MP, Szmuchrowski LA. Chronic effects of different frequencies of local vibrations. Int J Sports Med 2012; 33(2): 123-9.

3. Cochrane DJ. Does Muscular Force of the Upper Body Increase Following Acute, Direct Vibration? Int J Sports Med 2016; 37(7): 547-51.

4. Oliveira MP, Rodrigues SA, Szmuchrowski LA, Albuquerque MR, Gonçalves $\mathrm{R}$, Flor CAG, et al. Effects of local vibrations on muscle streng th and roundhouse kick performance of taekwondo athletes. Arch Budo 2017; 13: 23-33.

5. Martin BJ, Park HS. Analysis of the tonic vibration reflex: Influence of vibration variables on motor unit synchronization and fatigue. Eur J Appl Physiol Occup Physiol 1997; 75(6): 504-11.

6. Bogaerts A, Delecluse C, Claessens AL, Coudyzer W, Boonen S, Verschueren SMP. Impact of Whole-Body Vibration Training Versus Fitness Training on Muscle Strength and Muscle Mass in Older Men: A 1-Year Randomized Controlled Trial. Journals Gerontol Ser A 2007; 62(6): 630-5.

7. Rittweger J. Vibration as an exercise modality: how it may work, and what its potential might be. Eur J Appl Physiol 2010; 108(5): 877-904.

8. Rosenberger A, Beijer Å, Johannes B, Schoenau E, Mester J, Rittweger J, et al. Changes in muscle cross-sectional area, muscle force, and jump performance during 6 weeks of progressive whole-body vibration combined with progressive, high intensity resistance training. J Musculoskelet Neuronal Interact 2017; 17(2): 38-49.

9. Bunker DJ, Rhea MR, Simons T, Marin PJ. The use of whole-body vibration as a golf warm-up. J Strength Cond Res 2011; 25(2): 293-7.

10. Reyes GF, Dickin DC, Crusat NJK, Dolny DG. Whole-body vibration effects on the muscle activity of upper and lower body muscles during the baseball swing in recreational baseball hitters. Sport Biomech 2011;10(4): 280-93.

11. Bridge CA, da Silva Santos JF, Chaabene H, Pieter W, Franchini E. Physical and physiological profiles of taekwondo athletes. Sport Med 2014; 44(6): 713-33.

12. Rittweger J, Beller G, Felsenberg D. Acute physiological effects of exhaustive whole-body vibration exercise in man. Clin Physiol 2000; 20(2): 134-42.

13. Delecluse C, Roelants M, Diels R, Koninckx E, Verschueren S. Effects of whole body vibration training on muscle strength and sprint performance in sprint-trained athletes. Int J Sports Med 2005; 26(8): 662-8.

14. Munera M, Bertucci W, Duc S, Chiementin X. Transmission of whole body vibration to the lower body in static and dynamic half-squat exercises. Sport Biomech 2016; 15(4): 409-28.

15. Rubin C, Pope M, Chris Fritton J, Magnusson M, Hansson T, McLeod K. Transmissibility of 15-Hertz to 35-Hertz Vibrations to the Human Hip and Lumbar Spine: Determining the Physiologic Feasibility of Delivering Low-Level Anabolic Mechanical Stimuli to Skeletal Regions at Greatest Risk of Fracture Because of Osteoporosis. Spine 2003; 28(23): 2621-7.

16. Di Giminiani R, Tihanyi J, Safar S, Scrimaglio R. The effects of vibration on explosive and reactive strength when applying individualized vibration frequencies. J Sports Sci 2009; 27(2): 169-77.

17. Pérez-Turpín JA, Zmijewski P, Jimenez-Olmedo JM, Jové-Tossi MA, MartínezCarbonell A, Suárez-Llorca C, et al. Effects of whole body vibration on strength and jumping performance in volleyball and beach volleyball players. Biol Sport 2014; 31(3): 239-45. 
18. Couto BP, Costa GAS, Barbosa MP, Chagas MH, Szmuchrowski LA. Effect of application of mechanical vibration on vertical impulsion. Motriz 2012; 18(3): 414-22.

19. Torvinen, S, Sievänen, H, Järvinen, TAH, Pasanen, M, Kontulainen, S, Kannus P. Effect of 4-min vertical whole body vibration on muscle performance and body balance: a randomized cross-over study. Int J Sports Med 2002; 23(5): 374-9.

20. Bosco C, Iacovelli M, Tsarpela O, Cardinale M, Bonifazi M, Tihanyi J, et al. Hormonal responses to whole-body vibration in men. Eur J Appl Physiol 2000; 81(6): 449-54.

21. Pollock RD, Woledge RC, Martin FC, Newham DJ. Effects of whole body vibration on motor unit recruitment and threshold. J Appl Physiol 2012; 112(3): 388-95.

22. Kerschan-Schind1 K, Grampp S, Henk C, Resch H, Preisinger E, Fialka-Moser $\mathrm{V}$, et al. Whole-body vibration exercise leads to alterations in muscle blood volume. Clin Physiol 2001; 21(3): 377-82.

23. Cochrane DJ, Stannard SR, Firth EC, Rittweger J. Acute whole-body vibration elicits post-activation potentiation. Eur J Appl Physiol 2010; 108(2): 311-19.

24. Cormie P, Deane RS, Triplett NT, McBride JM. Acute effects of whole-body vibration on muscle activity, strength, and power. J Strength Cond Res 2006; 20(2): 257-61.

25. Cochrane DJ, Legg SJ, Hooker MJ. The short-term effect of whole-body vibration training on vertical jump, sprint, and agility performance. J Strength Cond Res 2004; 18(4): 828-32.

26. Lienhard K, Vienneau J, Nigg S, Meste O, Colson SS, Nigg BM. Relationship Between Lower Limb Muscle Activity and Platform Acceleration During WholeBody Vibration Exercise. J Strength Cond Res 2015; 29(10): 2844-53.

27. Di Giminiani R, Masedu F, Padulo J, Tihanyi J, Valenti M. The EMG activity-acceleration relationship to quantify the optimal vibration load when applying synchronous whole-body vibration. J Electromyogr Kinesiol 2015; 25(6): 853-9.

28. Cardinale MJL. The acute effects of two different whole body vibration frequencies on vertical jump performance. Med Sport 2003; 56: 287-92.

29. Carlucci F, Felici F, Piccinini A, Haxhi J, Sacchetti M. Individual Optimal Frequency in Whole-Body Vibration: Effect of Protocol, Joint Angle, and Fatiguing Exercise. J Strength Cond Res 2016; 30(12): 3503-11.

30. Luo J, McNamara B, Moran K. The Use of Vibration Training to Enhance Muscle Strength and Power. Sport Med 2005; 35(1): 23-41.

\section{CORRESPONDING AUTHOR}

Mariana Paulino Oliveira Universidade Federal de Minas Gerais

Av. Antônio Carlos, 6627,

Pampulha, Belo Horizonte, Minas Gerais, Brasil,

CEP 31270-901.

E-mail: maripaulinoliveira@gmail. com 